\title{
Assessment of minimally invasive surgical skills of pre-medical students: What can we learn from future learners?
}

\author{
Mostafa A. Borahay' ${ }^{1}$, Mary Jackson', Ömer L. Tapısız',2, Elizabeth Lyons ${ }^{3}$, Pooja R. Patel', Ramsey Nassar', Gökhan Sami Kılıçl \\ 'Department of Obstetrics and Gynecology, University of Texas Medical Branch at Galveston, Texas, USA \\ ${ }^{2}$ Department of Gynecologic Oncology, Etlik Zübeyde Hanim Women's Health Training and Research Hospital, Ankara, Turkey \\ ${ }^{3}$ Department of Psychology, Institute for Translational Sciences, University of Texas Medical Branch at Galveston School \\ of Medicine, Texas, USA \\ ${ }^{4}$ Taylor High School, Houston, Texas, USA
}

\section{Abstract}

Objective: Knowledge of baseline laparoscopic and robotic surgical skills of future learners is essential to develop teaching strategies that best fit them. The objectives of this study are to determine baseline laparoscopic and robotic skills of high school and college students and compare them to those of current obstetrics and gynecology residents.

Material and Methods: A cross-sectional (Class II-2) pilot study. Laparoscopic and robotic surgical skills of college and high (secondary) school students were evaluated using simulators and compared to those of obstetrics and gynecology residents. In addition, questionnaire data were collected regarding video game playing and computer use.

Results: A total of 17 students, both high school $(n=9)$ and college $(n=8)$, in addition to 11 residents, completed the study. Overall, students performed comparably to the residents in simple exercises ( $p>.05$ ). However, students took significantly longer time to complete complex exercises $(\mathrm{p}=.001)$. Finally, students played video games significantly more than residents $(\mathrm{p}<.001)$.

Conclusion: Future learners may have a different background skill set. This difference may be related to improved hand-eye coordination, possibly due to playing video games. The results of this pilot study should spur more research into surgical teaching strategies. (J Turk Ger Gynecol Assoc 2014; 15: 69-73)

Key words: Simulation, education, robotic surgery, laparoscopy, video games

Received: 06 May, 2014

Accepted: 08 May, 2014

\section{Introduction}

Laparoscopic and robotic-assisted procedures, collectively known as minimally invasive surgery (MIS), are rapidly gaining popularity in the field of gynecology. Compared to laparotomy, they offer several advantages, including improved postoperative recovery, decreased postoperative pain and hospital stay, better visualization, better cosmetic outcome, and decreased blood loss $(1,2)$. Surgeons who adopt MIS must undergo a learning curve, the steepness of which varies among individuals. This learning curve involves mastering the hand-eye coordination associated with a 2-D screen, a skill similar those developed during video game and computer use. In fact, reports have demonstrated that video game playing is associated with improved reaction time and spatial visualization (3-7). It is therefore conceivable that individuals who have more video game exposure may have a different set of baseline skills for performing MIS, which has been the subject of multiple reports $(8,9)$.

New surgical technologies are usually introduced to practicing physicians before reaching residency training programs. Only after initial studies demonstrate safety and effectiveness do educational institutions begin incorporating the technology into residency training. For example, the first laparoscopic hysterectomy was described in 1989 (10); however, it did not become part of residency training objectives until the 2000s. Robotic surgery training seems to be following a similar trend. Although it was Food and Drug Administration (FDA)-approved in 2005, it is not yet part of the Accreditation Council for Graduate Medical Education (ACGME) training objectives. As a consequence of this delay, current teaching strategies are targeted towards practicing physicians, an older generation, rather than the younger generation of current and future gynecologic trainees. These strategies may not be appropriate, however, as the younger generation may possess 
a distinct set of background skills, given their early exposure to technology, that may render the current teaching strategies obsolete.

With the current widespread use of video games, it is reasonable to assume that future MIS learners may have a different set of "background" skills, impacting the design of more effective MIS teaching strategies. In this cross-sectional study, we evaluated the MIS simulation performance of college and high school students, as a proxy for future learners, in correlation to their exposure to screen time, defined as personal computer or video game use. To the best of our knowledge, this is the first study that assesses MIS simulation skills in high school and college students.

\section{Material and Methods}

The study was approved by the Institutional Review Board (IRB) at the University of Texas Medical Branch. This work was carried out in accordance with the Declaration of Helsinki, including, but not limited to, there being no potential harm to participants, guarantee of anonymity of participants, and informed consent from participants. This cross-sectional study included 3 groups of participants: high school students, college students, and obstetrics and gynecology residents. Questionnaires were used to obtain background information about the study subjects. The survey included questions about the subjects' education or PGY levels, years of computer use, and video game playing. Game use was further detailed by determining the number of gaming hours each day of the week, as well as average daily and weekly use. Furthermore, the types of consoles used e.g. Xbox (Microsoft Corporation, Redmond, WA, USA), PlayStation (Sony Corporation, Minato, Tokyo, Japan), personal computer, or Wii (Nintendo, Kyoto, Japan) and types of games played (war games, car racing, sports games, strategy games, or other) were delineated. Subjects were also asked how many minutes per day they used their computers, both for personal use and homework.

MIS simulation exercises were then performed, and data were recorded and analyzed. We used the Mimic Technologies dVTrainer platform (Mimic Technologies Inc, Seattle, WA, USA) for robotic simulation and the 3-Dmed Trainer platform (3-DMEd, Franklin, OH, USA) for laparoscopic simulation testing. Four robotic exercises mimicking EndoWrist manipulation were performed: "Pick and Place," "Ring and Rail," "Match Board1," and "Peg Board-1." For laparoscopic simulation testing, we used the "Loops and Wire" exercise. Time to complete each exercise was recorded.

\section{Statistical Analysis}

All variables were examined for unusual and missing values using dot plots for each variable. Medians, interquartile ranges, and minimum and maximum values were examined for each of the background variables by group (High School, College, or Resident). A one-way analysis of variance procedure for nonparametric data (Kruskal-Wallis U test) was used to assess whether the variation among groups was significant for each of the variables. Separate pairwise comparisons for each group of subjects were performed using a Bonferroni adjustment. Data were analyzed using SAS Software, v. 9.2 (SAS Institute Inc., Cary, NC, USA).

\section{Results}

A total of 17 students, both high school $(n=9)$ and college $(n=8)$, were enrolled in this study. In addition, a group of obstetrics and gynecology residents $(n=11)$ was included for comparison. As expected, the age range was significantly different among groups $(\mathrm{p}<.001)$.

Results of the laparoscopic and robotic simulation assessment are presented in Table 1. Pairwise comparisons with Bonferroni adjustment show that students took significantly longer time than residents to complete laparoscopic exercises $(p=.027)$. However, the time needed by students to complete robotic simulation exercises was not statistically significant from residents (p-values ranged from .319 to .967). Only the Peg Board exercise showed a longer time to complete for high school students compared to residents $(p=.006)$.

Given that the students' performance was close to that of residents in robotic simulation, we also analyzed screen time exposure. Background characteristics are shown in Table 2, where variables are presented as medians and interquartile ranges and stratified by group. Kruskal-Wallis tests showed that number of years of computer use, minutes of daily personal computer use, and minutes of weekly video game playing differed

Table 1. Age and screen time data

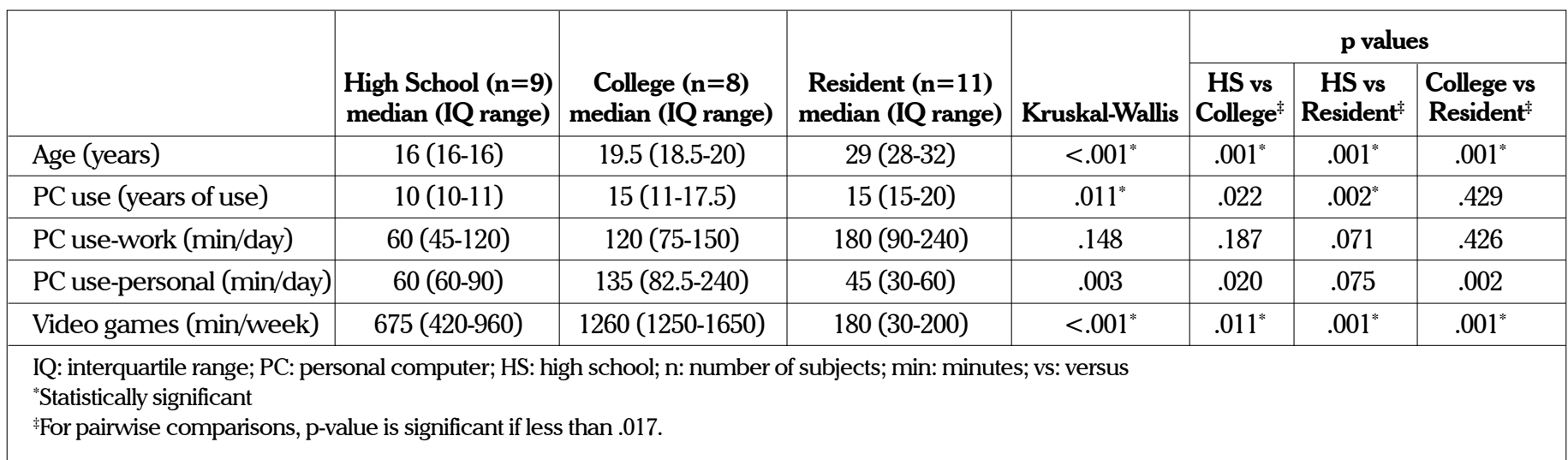


Table 2. Percentage of gaming time by game console and game type ${ }^{\dagger}$

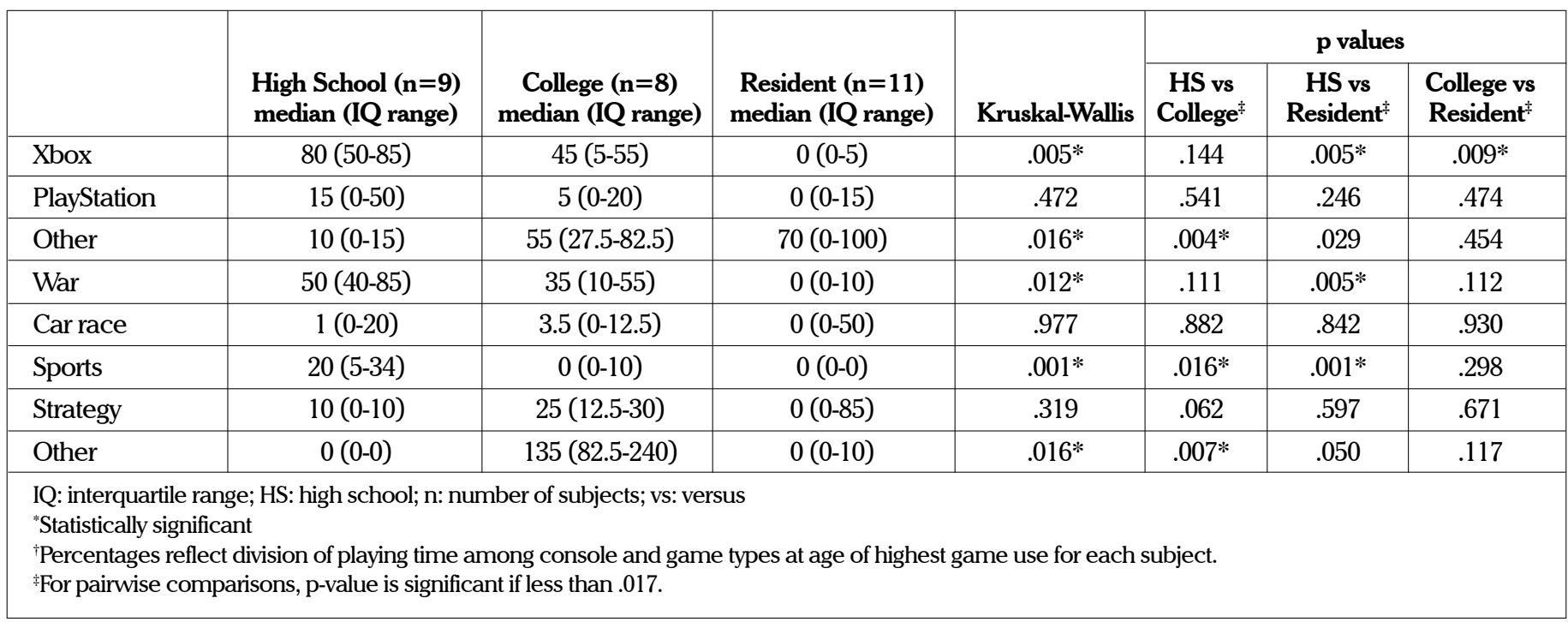

Table 3. Minimally invasive surgery (MIS) simulation exercises data- time to completion in seconds

\begin{tabular}{|c|c|c|c|c|c|c|c|}
\hline & $\begin{array}{l}\text { High School }(n=9) \\
\text { median (IQ range) }\end{array}$ & $\begin{array}{c}\text { College }(n=8) \\
\text { median (IQ range) }\end{array}$ & $\begin{array}{l}\text { Resident ( } n=11) \\
\text { median (IQ range) }\end{array}$ & Kruskal-Wallis & \multicolumn{3}{|c|}{ p values } \\
\hline Ring and Rail & $58(58-64)$ & $62(25.5-76)$ & $62(51-70)$ & .967 & .772 & 1.000 & .869 \\
\hline Match Board-1 & $35(31-45)$ & $38.5(29.5-43.5)$ & $45(26-48)$ & .693 & .962 & .543 & .408 \\
\hline Loops and Wire & $159(90-208)$ & $74.5(67.5-91)$ & $55(40-75)$ & $.001^{*}$ & $.027^{*}$ & $.001^{*}$ & $.035^{*}$ \\
\hline $\begin{array}{l}\text { IQ: interquartile ran } \\
\text { "Statistically signific } \\
{ }^{*} \text { For pairwise comp }\end{array}$ & e; HS: high school; n: nu & $\begin{array}{l}\text { aber of subjects; vs: vel } \\
\text { nt if less than } .017\end{array}$ & & & & & \\
\hline
\end{tabular}

among groups (p-values .0105, .0026, and <.001, respectively). Subsequently, we analyzed study groups according to types of consoles used and video games played (Table 2,3). Our results show that high school and college students played the Xbox game console more than residents. The most common games played by high school students were war games, followed by sports and then strategy games, while college students mostly played other game types, followed by war and then strategy. High school students played statistically significantly more war games than residents. Of note, Xbox game use, other game console use, war games played, sports games played, and other types of games played were all significantly different among the 3 groups.

\section{Discussion}

The results of this study show that high school and college students' performance in basic MIS skills is comparable to residents. Initially, these results may seem unexpected; however, our finding that current students have more exposure to video games than residents have had in the past may provide an explanation. These findings are important, as they may influence the way training programs are developed. We should emphasize that this is an initial pilot study that should spur larger-scale research in the field.

While our study is the first to assess MIS skills in nonmedical students, it is not the first to address the possible relationship of video games to MIS skills. In fact, several reports have been published in this area in recent years. For example, Shane et al. (11) showed that in a group of 26 medical students and first-year residents, individuals with previous video game experience took significantly less time to reach proficiency in laparoscopic skills than individuals without previous video game use. In 2 separate studies, Rosenberg et al. (8) and Glaser et al. (12) showed that in groups of 11 and 26 medical students, respectively, video game use correlated with both hand-eye coordination and reduced completion time for simple laparoscopic tasks. A potential bias with these studies, however, is the fact that prior exposure to laparoscopic surgery was not assessed. As medical students are exposed to MIS (both robotic and laparoscopic surgery) during their training, a study in younger students would be more pertinent. High school and college students, for example, 
are less likely to be exposed to MIS. Clearly, a study comparing MIS skills in these students to those in residents who have already had some training would better assess the influence of video games on MIS skills.

Different types of video games likely produce different effects. Most studies of the cognitive effects of games have used action or "fast-action" games, typically first-person shooters, like the war games played by the students in this study $(13,14)$. In addition to shooter/war games, other games, such as Super Monkey Ball, which require complex navigation through virtual worlds, have successfully improved performance during surgical simulations (15-17).

These findings contribute to a growing body of literature investigating the potential of video games to influence visuospatial skills and psychomotor performance. Visual attention skills were shown to be higher in video game players than nonplayers in studies in both adults and children (18), with differences found in samples as young as 7 years old (19). The range of beneficial effects in studies that have tested video game training in nongamers suggests that these training effects may accrue in as little as 10 hours $(15,16)$ or may require longer periods of habitual use (17). Whether game-based training during childhood or adolescence may confer additional benefits over training in adulthood is an intriguing empirical question.

As previously mentioned, this study is a preliminary investigation; thus, its results must be interpreted with caution. The small sample size may have lacked sufficient power to detect differences among groups in their skills tests. There may also be unmeasured variables that contributed to these findings. It is possible that pre-existing differences in skills between those who choose to play games versus nongamers may confound the relationship between gaming and skill. Gender also may have played a contributing factor in producing these results. The students were male, while our sample of residents was mostly female (8/11). Though gender differences in visuospatial skills have been found in many studies, rigorous randomized controlled trials have shown that training women with action video games for as little as 10 hours can nearly eliminate gender differences (15). In fact, video-game-based spatial training may be as effective (19) or more effective (20) in women than men. Because action and shooter video games are typically marketed to and played by males, gender disparities are likely perpetuated by greater opportunities for skills training for young men (21). Balanced designs with larger samples are necessary to investigate how gender and gaming experience may interact in predicting surgical simulator performance.

As Spence and Feng (14) have pointed out, a major value of observational studies is in exploring fruitful new areas for subsequent research. Future studies are necessary to investigate potential cohort effects related to habitual video game use during childhood, the potential of video game-based interventions to increase surgical skills prior to residency, and the effectiveness of different educational strategies on gamers and nongamers.

Do we need to adapt our teaching strategies to fit the skills future learners already have? Clearly, we need to further investigate trends in hand-eye coordination in younger generations, which may lead to more successful teaching programs that use and build on skills already acquired. In addition, we can guide video game developers to create games that intentionally improve hand-eye coordination skills. It is intuitive to expect that such skills will not only improve MIS skills but also be advantageous to other professions requiring similar skills (eg, pilots, graphic designers, etc). Finally, we believe there should be close collaboration with developmental psychologists in building more effective MIS teaching strategies.

Ethics Committee Approval: Ethics committee approval was received for this study from the Institutional Review Board (IRB) at the University of Texas Medical Branch.

Informed Consent: Written informed consent was obtained from participants for this study.

Peer-review: Externally peer-reviewed.

Author contributions: Concept - M.B., M.J., O.T., G.K.; Design - M.J., O.T., R.N., G.K.; Supervision - M.J., O.T., R.N., G.K.; Resource - M.B., E.L., G.K.; Materials - M.J., O.T., R.N., G.K.; Data Collection\&/or Processing - M.J., O.T., R.N., G.K.; Analysis\&/or Interpretation - M.B., M.J., O.T., G.K.; Literature Search - M.B., M.J., O.T., E.L., P.P.; Writing - M.B., O.T., M.J., P.P., G.K.; Critical Reviews - E.L., P.P., GK.

Conflict of Interest: No conflict of interest was declared by the authors

Financial Disclosure: This work was partially funded by an educational technology grant for Dr. Mostafa Borahay from the Academy of Master Teachers at the University of Texas System. Dr. Elizabeth Lyons is supported by NIH career development award (K12HD052023) and the Institute for Translational Sciences at the University of Texas Medical Branch.

\section{References}

1. Li X, Zhang J, Sang L, Zhang W, Chu Z, Li X, Liu Y. Laparoscopic versus conventional appendectomy -- a meta-analysis of randomized controlled trials. BMC Gastroenterol 2010; 10: 129. [CrossRef]

2. Sauerland S, Jaschinski T, Neugebauer EA. Laparoscopic versus open surgery for suspected appendicitis. Cochrane Database Syst Rev 2010; CD001546.

3. Nielsen U, Dahl R, White RF, Grandjean P. [Computer assisted neuropsychological testing of children]. Ugeskr Laeger 1998; 160: 3557-61.

4. Griffith JL, Voloschin P, Gibb GD, Bailey JR. Differences in eye-hand motor coordination of video-game users and non-users. Percept Mot Skills 1983; 57: 155-8. [CrossRef]

5. Yuji H. Computer games and information-processing skills. Percept Mot Skills 1996; 83: 643-7. [CrossRef]

6. De Lisi R, Wolford JL. Improving children's mental rotation accuracy with computer game playing. J Genet Psychol 2002; 163: 272-82. [CrossRef]

7. Dorval M, Pepin M. Effect of playing a video game on a measure of spatial visualization. Percept Mot Skills 1986; 62:159-162. [CrossRef]

8. Rosenberg BH, Landsittel D, Averch TD. Can video games be used to predict or improve laparoscopic skills? J Endourol Apr 2005; 19: 372-6. [CrossRef]

9. Lynch J, Aughwane P, Hammond TM. Video games and surgical ability: a literature review. J Surg Educ 2010; 67: 184-9. [CrossRef] 
10. Reich H, DeCaprio J, McGlynn F. Laparoscopic hysterectomy. J Gynecol Surg 1989; 5: 213-6. [CrossRef]

11. Shane MD, Pettitt BJ, Morgenthal CB, Smith CD. Should surgical novices trade their retractors for joysticks? Videogame experience decreases the time needed to acquire surgical skills. Surg Endosc 2008; 22: 1294-7. [CrossRef]

12. Glaser AY, Hall CB, Uribe SJ, Fried MP. The effects of previously acquired skills on sinus surgery simulator performance. Otolaryngol Head Neck Surg 2005; 133: 525-30. [CrossRef]

13. Green CS, Bavelier D. Learning, attentional control, and action video games. Curr Biol 2012; 22: R197-206. [CrossRef]

14. Spence I, Feng J. Video games and spatial cognition. Rev Gen Psychol 2010; 14: 92-104. [CrossRef]

15. Feng J, Spence I, Pratt J. Playing an action video game reduces gender differences in spatial cognition. Psychol Sci 2007; 18: 850-5. [CrossRef]
16. Green CS, Bavelier D. Action-video-game experience alters the spatial resolution of vision. Psychol Sci 2007; 18: 88-94. [CrossRef]

17. Boot WR, Kramer AF, Simons DJ, Fabiani M, Gratton G. The effects of video game playing on attention, memory, and executive control. Acta Psychol (Amst) 2008; 129: 387-98. [CrossRef]

18. Dye MW, Bavelier D. Differential development of visual attention skills in school-age children. Vision Res 2010; 50: 452-9. [CrossRef]

19. Dye MW, Green CS, Bavelier D. The development of attention skills in action video game players. Neuropsychologia 2009; 47: 1780-9. [CrossRef]

20. Uttal DH, Meadow NG, Tipton E, Hand LL, Alden AR, Warren C, Newcombe NS. The malleability of spatial skills: a meta-analysis of training studies. Psychol Bull 2013; 139: 352-402. [CrossRef]

21. Cherney ID. Mom, let me play more computer games: They improve my mental rotation skills. Sex Roles 2008; 59: 776-86. [CrossRef] 